\title{
Dos años de gobierno del FMLN: promesas, resultados y calificación de la gente
}

\begin{abstract}
El Gobierno tiene una tarea formidable para recuperar su imagen, la que no se logra con avisos comerciales, sino que generando resultados, cumpliendo promesas, escuchando a la gente y alejándose de la confrontación. Sin dudas, llegó el momento de actuar con sensatez, de reflexionar y corregir.
\end{abstract}

Marco conceptual

$\mathbf{E}^{\prime}$ progreso socioeconómico de un país se logra de mejor manera si se crea el círculo virtuoso donde el crecimiento económico genera recursos para el progreso social y éste resulta en personas con mejor preparación para contribuir a un mayor crecimiento económico. Por esto es tan importante que la economía crezca, porque así las empresas y las familias ganan, consumen e invierten, todo lo cual eleva la recaudación tributaria, para invertir — principalmente en educación y salud de calidad — esto es en capital humano.

Desde el punto de vista económico, el crecimiento se loga en la medida que; (i) hay mayor consumo, donde el privado (consumidores) es clave; (ii) hay altos niveles de inversión privada y pública; (iii) y hay una estrategia que estimule la ampliación de las exportaciones, esto es, para recibir mayores ingresos provenientes del extranjero.

En el ámbito externo, las remesas familiares también juegan un papel preponderante en la captación de recursos externos para estimular la economía nacional, pero ellos deben verse como un factor para ganar tiempo estratégico, mientras se conquistan nuevos mercados para las exportaciones nacionales. Por tanto, ellas deben observarse como un factor positivo "temporal" y no contar con ellas como fuente de ingreso de largo plazo. Las mayores dificultades y las reformas migratorias que se están manifestando en Estados Unidos de América, en respuesta a un ambiente de rechazo de los inmigrantes ilegales, muestran que el crecimiento de las remesas será cada vez más difícil de mantener en el largo plazo. Lo más probable es que haya una tendencia a que las remesas familiares se desaceleren y luego se reduzcan paulatinamente.

Herencia de las transformaciones de los últimos 20 años

El Salvador se transformó durante los últimos 20 años, lo cual es fácil de observar si se aleja de las posiciones preconcebidas de orden ideológico. 
Desde fines de los 70, El Salvador vivió un período de agudas contradicciones socioeconómicas y políticas, caracterizado por un conflicto armado, como reflejo del alto grado de intolerancia que mostró la sociedad salvadoreña. La situación del país se agravó por la fuerte crisis económica que nació de la incertidumbre que ocasionaba el conflicto, la destrucción de la infraestructura y de las fuentes de producción, así como por el irrespeto por la vida de las personas. Todo exacerbado por la implantación de políticas "estatistas intervencionistas" que violaron el derecho de propiedad privada, en medio de una fuerte recesión económica mundial.
En los 80 's, el estatismo ahogó la iniciativa creadora del sector privado: (i) las principales fuentes de producción y de servicios fueron usurpadas por el Estado: reforma agraria y nacionalización del comercio externo y de la banca; (ii) grandes déficit del sector público fueron financiados, en proporciones crecientes, con recursos domésticos: se desplazó al sector privado y puso presión en los precios internos; (iii) el país era como una isla incomunicada con el mundo, sólo reconocida por la violencia y como lugar de alto riesgo; y (iv) hubo una alta fuga de capitales, al tiempo que la inversión privada, en gran proporción, se fue del país.

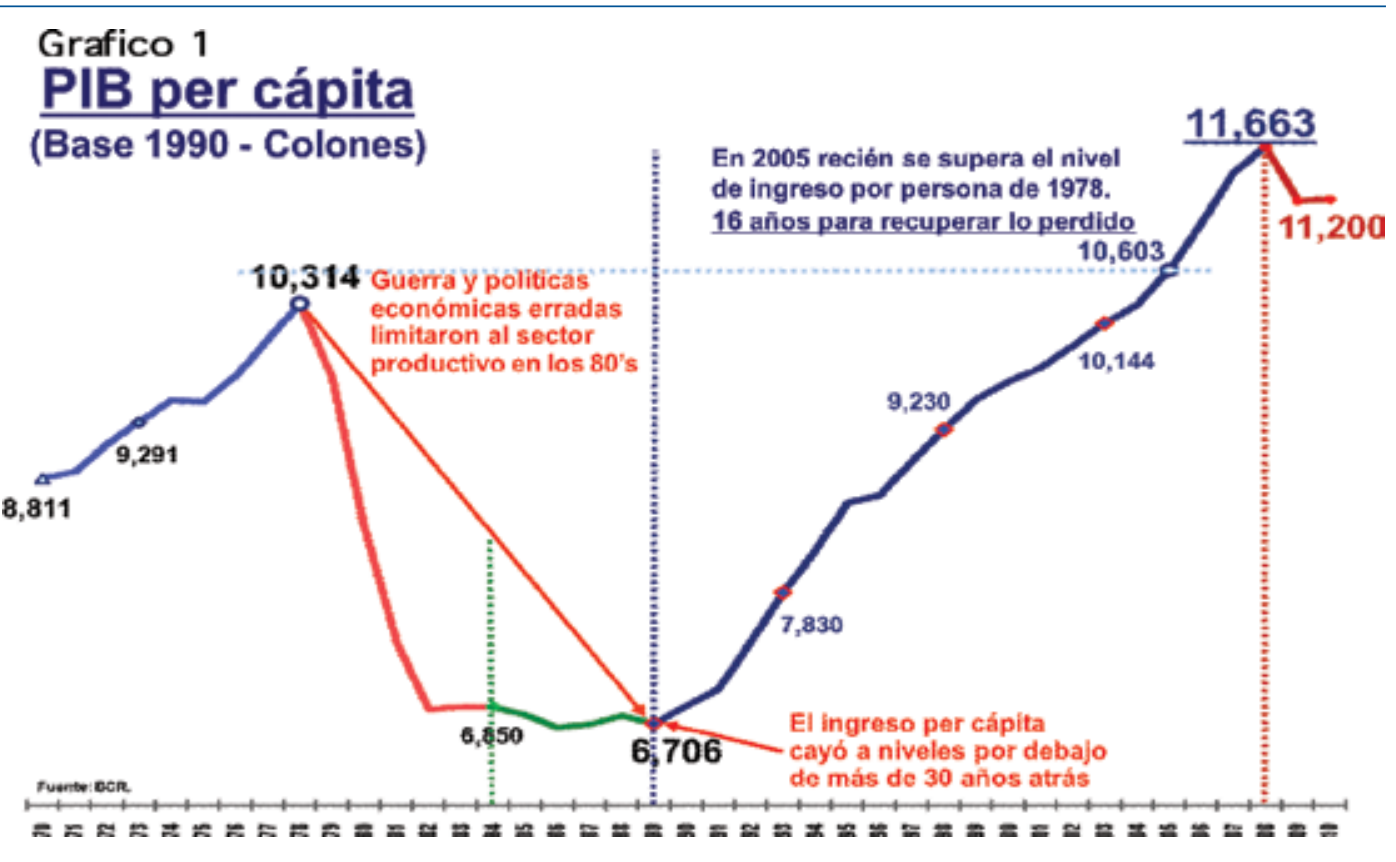

Hubo una fuerte intervención estatal en la vida económica, donde había que solicitar permisos para importar, exportar y comprar dólares; el otorgamiento de crédito al sector privado fue politizado y su acceso fue limitado, en medio de una creciente corrupción. Déficit fiscales sin control y altos impuestos asfixiaban al sector privado y ponían presión al costo de vida, de modo que el IPC aumentó 468,5\% entre 1980-89, al tiempo que el ingreso real per cápita cayó y el subempleo afectaba a la mitad de la Población
Económicamente Activa. En ese entorno, la pobreza, el analfabetismo y el desempleo llegaron a niveles récord, con tendencia a aumentar, lo que causó que el país se empobreciera social y económicamente: El Salvador retrocedió más de 30 años y los expertos internacionales consideraban que se necesitaría 50 años para recuperarse. Pero en 16 años se transformó la economía, se contuvo la caída real del ingreso por persona y todos los indicadores sociales mostraron una marcada mejoría (Gráfico 1 y Cuadro 1). 
Si bien se logró la paz, se estableció un sistema de libertades y hubo un progreso importante, en el transcurso del gobierno anterior, el populismo, graves señalamientos de corrupción y la recesión mundial crearon condiciones favorables para un cambio de gobierno, lo que abrió paso al triunfo electoral del FMLN, con un candidato que se alejó de la ortodoxia, hizo grandes promesas y, así, levantó una gran esperanza. Con este triunfo de la izquierda, la democracia dio otro paso importante, porque se materializó un proceso de alternancia que se ponía en duda.

\section{Cuadro 1. Principales indicadores económicos}

1989

- PIB (crecimiento): $1,1 \%$

- IPC - Tasa de inflación: $18,0 \%$

- Desempleo urbano: $9,4 \%$

- Tasa de subempleo: $50,0 \%$

- Aumenta pobreza y afecta a: $61 \%$ de los hogares

- 80-89: Ingreso real se desploma 2/3 en la década

- Déficit Fiscal (\%PIB) $4,7 \%$

- Excl. Donaciones: $5.9 \%$

- Recaudación tributaria (\%PIB): 7,8\%

- Deuda pública total (\%PIB): $47,0 \%$

- Órdenes Legalizadas Pendientes de Pago: \$1.416 mm

- RIN: \$20 millones

- Mora externa a mayo: $\$ 160$ millones

- Exportaciones: $\$ 576$ millones

- Permisos para importar y comprar divisas

- Crédito al sector privado: $20,9 \%$ del PIB

- Tasa interés (corto plazo): $20,21 \%$

- Cartera bancos en mora: $36,7 \%$

- Analfabetismo: $32,1 \%$ de la población es analfabeta

- Baja cobertura, escuelas destruidas y abandonadas

- Deporte abandonado

- Creciente déficit de vivienda: 4 millón 48 mil viviendas

- Cobertura de agua: $51.9 \%$ de hogares con agua de cañería

- Energía eléctrica estatal: $69.3 \%$ de hogares con electricidad

- Telefonía estatal: 122 mil teléfonos y pasaban años para obtener una línea y altas tarifas

- 97 mil vehículos

\section{Evaluación: a dos años del gobierno del FMLN}

Han pasado dos años del gobierno del FMLN, presidido por don Mauricio Funes y toca evaluar su gestión, la que

\section{8}

- PIB (crecimiento): 4,7\% 2007; 2,5\% 2008 (en recesión)

- $1,2 \%$ a mayo $2009: 15$ veces menos

- $5,8 \%$ en $2007 ; 5,5 \%$ (2008)

- $28.4 \%(2007), 32.1 \%(2008)$

- Se reduce 11 puntos: $36,4 \%$ en 2008 (30,7\% en 2006)

- Ingreso real se mantiene

- Déficit 3,1\% (\% PIB)

- Excl. Donaciones: no aplica

- Recaudación: $13,4 \%$ en $2007 ; 13,0 \%$ en 2008

- Deuda pública: $35,7 \%$ (2008)

- Órdenes legalizadas pendientes de pago: no aplica.

- RIN: $\$ 2.541 \mathrm{~mm}$, récord histórico a esa fecha

- No existe

- Exportaciones: $\$ 4.549$ millones (2008): 7,9 veces más

- No aplica; no las pide porque están en manos del público

- Crédito al sector privado: bancos residentes $41,7 \%$ del (2008); incluyendo bancos no residentes: $53,2 \%$

- Tasa interés (corto plazo): $9,38 \%$

- Cartera bancos en mora: $2,8 \%$

- $13,9 \%$ de la población es analfabeta

- EDUCO llega a más 1.700 comunidades, con 4.400 maestros: gana premio mundial a la excelencia del Bco. Mundial; y Escuela Saludable da servicios de salud a más de 1 millón de niños/as.

- Somos líderes en CA

- 1 millón 620 mil viviendas... 620 mil nuevas viviendas cuando los hogares aumentaron en 340 mil

- $78,7 \%$ con conexiones de agua por cañería

- Distribución privada: $91 \%$ de hogares con electricidad

- Telefonía privada: 7.8 millones de líneas en 2008 y 8,7 millones en 2009, líneas inmediatas y bajas tarifas

- 674 mil vehículos por crecientes clases medias

se debe hacer sobre la base de dos enfoques diferentes: (i) el cumplimiento de sus principales promesas electorales y (ii) la evaluación que le da la población a su gestión. Es importante destacar que a los dos años de gobierno, que 
en el caso de El Salvador equivalen al $40 \%$ del período de gestión, ya se deben haber cumplido o realizado la inmensa mayoría de las ofertas electorales, porque este es el tiempo cuando el gobernante utiliza su capital político y toda la energía de un equipo que aspira marcar la diferencia con el gobierno anterior y que busca destacarse por la ejecución de proyectos y los resultados positivos que con ellos se logren.

Para calificar la gestión de manera objetiva se emplea un mecanismo donde si la promesa tiene menos de $20 \%$ de ejecución se considera "no cumplida"; si tiene cumplido entre $21 \%$ y $85 \%$ se califica como "en proceso de cumplimiento"; y si ya ha logrado ejecutar más de $85 \%$ se considera "cumplida". Esta forma de medir aplica los conceptos tipo Politifact, en el cual no se consideran factores externos al dominio del gobierno, como pueden ser: no aprobación de leyes por el Congreso, falta de recursos o cualquier otra razón que lo limite, porque se estima que quien promete, conoce a fondo la situación del país. Usando esta conocida forma de calificar, no se pretende aquí hacer la evaluación sino dejarlo al criterio del lector. En este ejercicio, dé un punto por promesa "cumplida", $1 / 2$ por "en proceso" $y$ "0" por incumplida y tendrá su evaluación.

\section{Las 15 promesas principales}

1. Dar uniformes, zapatos y útiles escolares.

2. Ciudad Mujer. Hay una sola; prometió una en cada cabecera departamental.

3. "Programa Madre Feliz para garantizar todo el apoyo que las mujeres necesitan durante el embarazo y hasta los primeros cinco años de vida del niño (incluyendo) medicinas gratis, ayuda alimentaria y transporte para consultas y exámenes regulares.
4. "Programa Primer Empleo", "con capacitación para nuestros jóvenes".

5. "Creación de la Fábrica de Empleos", con "100.000 empleos directos en los próximos 18 meses".

6. “Construcción y mejoramiento de 25 mil viviendas urbanas" en 18 meses.

7. “Reactivación de nuestra producción agrícola y ganadera (y) generar más de 35 mil empleos." Pero, no se generan los empleos y cae producción de granos básicos.

8. “Reforestación de la cuenca del río Lempa... empleos a 10 mil personas."

9. “Entregar 'todos' los títulos de propiedad de la tierra, ya en el primer año de gobierno".

10. "Reduciremos el costo de la vida".

11. Al Gobierno (de Saca) "no le preocupa la angustia de la gente que no tiene qué darle de comer a sus hijos... nosotros sí sabemos qué hacer... aumentar la producción local de alimentos... organizar sistemas de distribución de alimentos a precios más baratos".

12. "Para las autoridades de seguridad pública, que hoy se cometan dos o tres asesinatos menos al día de los que se cometían hace tres años eso es un éxito... sólo cuando dejemos de vivir en la zozobra diaria... podremos hablar que las políticas de combate a la delincuencia están dando resultados... mientras eso no ocurra, el fracaso es visi-ble y la necesidad del cambio se acrecienta cada vez más"... Nosotros sí combatiremos la delincuencia... (11/ nov/07). "Las maras, las pandillas, no pueden continuar actuando y creciendo impunemente". Pero, los homicidios aumentan de promedio de 9.1 casos por día en 2007-08 (3.335 casos al año) a 11.5 en 2009-10 (4.213 al año, 26.3\% más).

13. Abastecimiento de medicinas en los hospitales. A dos años, viceministra reconoce desabastecimiento. Faltan entre 10, 15 hasta 60 medicamentos, según el 
establecimiento. Se estima que de cada tres medicinas recetadas pacientes reciben en promedio sólo una.

14. "No estoy proponiendo incremento de impuestos, ni nuevos impuestos, ni incremento de tasas impositivas, no por razones electorales, por una razón de justicia tributaria... me parece injusto aumentar el IVA o poner un impuesto más, mientras no combatamos la elusión, la evasión y el contrabando".

15. “El bien público no puede ser confundido con el bien personal... Transparencia, combate a la corrupción y todas las formas de despilfarro y desvío del dinero público serán cosas sagradas en nuestro gobierno". Nota: hay acusaciones de corrupción no investigadas como por ejemplo: "Recibimos presiones de la Presidencia de la República... asignar paquetes agrícolas, ya negociados a cambio de apoyo legislativo... con GANA y PCN" (Manuel Sevilla, ex ministro de Agricultura) y reconocido por el diputado Lorenzana; ..."mi salida es... de típica corrupción, por asignación sin licitación de \$20 millones en publicidad a Polistepeque (Francisco Gómez, ex presidente de ANDA); posible violación de Ley de Ética Gubernamental (Art. 6): servidores públicos "no podrán pedir o recibir dádivas, beneficios o favores", y usó jet "prestado" para viaje a Orlando.

Lamentablemente, los contrastes entre lo prometido y las excusas después de las elecciones son causas del desprestigio generalizado de la función política. Evidentemente le quita valor a cualquier ser humano el no tener "palabra", esto es, decir algo, comprometerse y no tener reparos en no cumplir. Por tanto, esto aplica a cualquier profesión o actividad de la persona, pero se hace más relevante cuando se ejerce la función política, que debe ser entendida como "servir" a la gente, sin engaños.
Economía: marcada recuperación externa y débil evolución interna

\section{Anuncios incumplidos y plan anticrisis no ayudaron a una recuperación}

La profunda recesión económica y financiera mundial también golpeó a El Salvador a partir de mediados de 2008 y mostró su mayor impacto adverso en 2009. En este contexto, el 1 de junio, el presidente Mauricio Funes dijo: “Estamos lanzando El Plan Global Anticrisis... para garantizar la estabilidad de la economía y minorar los problemas sociales... Cuatro grandes objetivos guían nuestro plan: Resguardar los empleos existentes y generar nuevas fuentes de trabajo; proteger a los sectores poblacionales más vulnerables de los efectos negativos de esta crisis; aprovechar esta crisis para impulsar políticas de estado en materia social y económica e iniciar la construcción de un sistema de protección universal para todas las mujeres y para todos los hombres de nuestro país".

Seguidamente agregó: "En el área del empleo y apoyo a la producción, el plan contempla (1) la generación de 100 mil empleos directos en los próximos 18 meses. Entre las medidas más importantes se encuentran la ejecución de un (2) programa de empleo temporal, (3) la realización de un programa de ampliación y mejoramiento de servicios públicos e infraestructura básica y la (4) construcción y mejoramiento de 25 mil viviendas urbanas y (5) 20 mil soluciones de techo y piso en comunidades rurales, en municipios en condiciones de pobreza severa". En el área crediticia, el plan contempla la (6) creación inmediata de la banca estatal para el fomento productivo...". "La segunda medida es la (7) garantía y extensión temporal de los beneficios de acceso a los servicios de salud del Seguro Social para personas que 
cotizan y que hayan perdido su empleo... Y la tercera medida es la (8) eliminación de cuotas en el acceso a servicios de salud pública y la (9) dotación inmediata de medicamentos esenciales a todos los establecimientos del sistema público de salud. No más unidades ni hospitales sin medicinas... (ellos) tendrán el cuadro básico de medicamentos."

Lamentablemente, en el Informe de Labores del Presidente de la República, presentado el 1 de junio de 2011, no se mencionaron mayormente estos nueve anuncios hechos dos años antes. Probablemente porque en realidad sólo el "eliminación de cuotas en el acceso a servicios de salud pública" fue cumplido cabalmente y de los otros ochos no hubo avances significativos. Así, las medidas de reactivación económica anunciadas no tuvieron el impacto esperado. Además, en vez de tomar medidas económicas anticíclicas, el gobierno del FMLN introdujo un Paquete Tributario, esto es, implementó una acción pro cíclica, que acentuó la crisis y la economía terminó contrayéndose 3,1\% en 2009.

Así se tiene que pasado dos años de Gobierno del FMLN es evidente que el plan anticrisis que implementó no revertió la recesión, de la cual se tendió a salir con debilidad hacia fines de 2010, principalmente por efectos "externos", como el crecimiento de la economía de Estados Unidos de América y la recuperación de las economías centroamericanas, a los que se suman el esfuerzo del sector privado salvadoreño.

Así es como el promedio móvil de 12 meses de la tendencia ciclo del índice del volumen de actividad económica, IVAE, la mayor aproximación al PIB anual según el BCR, después de iniciar una tendencia a la contracción a partir de la segunda mitad de 2007, llegó a tocar fondo con $-8,71 \%$ de decrecimiento en abril de 2009, contrario a mostrado por el BCR durante meses, que señalaban que se había tocado fondo entre octubre-diciembre de ese año. Sin embargo, las nuevas cifras muestran una evolución positiva a partir de marzo de 2010, después de numerosos "ajustes", por períodos de hasta cinco años (¿?), para acercarse lo más posible al dato final de crecimiento del PIB para 2010.

En 2010, la economía salvadoreña mostró señales de una recuperación "estadística" hacia el final primer semestre, liderada por el sector externo, mientras los indicadores de actividad económica interna se mantuvieron débiles. Si bien el primer dato firme del BCR indicaba que la economía creció $0,7 \%$ real en 2010 -porcentaje que ya fuera considerado como inflado, dada la evolución de todos los otros indicadores macroeconómicos-, este fue sometido a un "ajuste estadístico", partiendo de los años anteriores, lo que dio como resultado un crecimiento económico de $1,4 \%$, sin que esto realmente hubiera significado un mayor crecimiento en la realidad, dado que familias y empresas no sintieron que esto sucediera. Las primeras mostrando una contracción del gasto y las segundas viviendo mes a mes

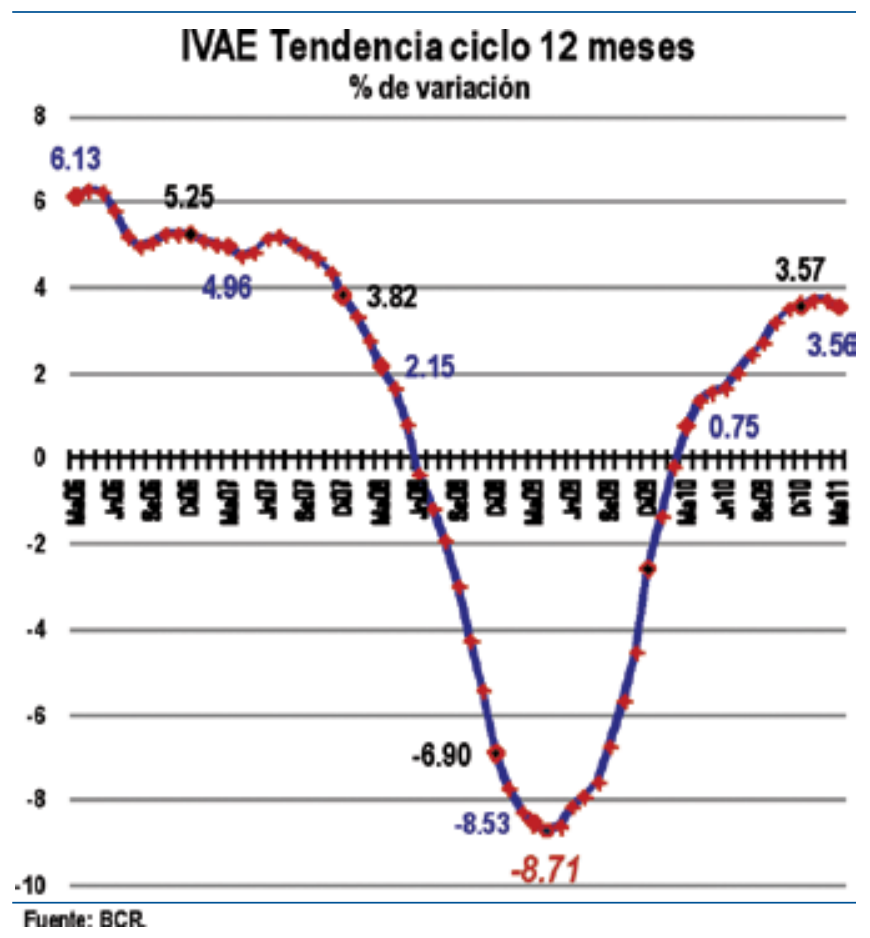


entre la vida y la muerte, asfixiados por la sequía de caja, las presiones de proveedores y esfuerzos para cumplir con el pago de planilla cada quince días.

\section{Inflación repunta liderada por Canasta Básica}

La inflación se mantuvo baja durante el segundo semestre de 2009, se elevó en el primer trimestre de 2010, en buena parte como resultado de la Reforma Tributaria, así como ajustes a la electricidad. Luego, a mediados de año, se inicia un leve pero creciente camino de aumento de la inflación, en gran parte por el alza de precios de los combustibles en el mercado mundial, situación agravada por un fuerte aumento de los precios de granos básicos, que se dio por una combinación de bajo rendimiento - que causó que la producción de frijol, maíz y sorgo de las cosechas 20092010 y 2010-2011 cayeran por debajo de las alcanzadas en 2008-2009- por la entrega atrasada y politizada de granos básicos, así como un régimen de lluvias que no fue favorable para los cultivos.

La baja producción de granos básicos impactó la canasta básica alimentaria —considerado el índice de Precios al Consumidor de las familias de menores ingresos-, causando un aumento de su costo en $\$ 20.30$, esto es, $12,3 \%$ en 2010 , poniendo presión en los presupuestos familiares urbanos. Además, la canasta básica "rural" subió \$12.79, esto es $10,8 \%$ en 2010 , y luego se eleva a $\$ 139.9$, que equivale a un alza de $17,7 \%$, resultado que golpea donde hay mayor pobreza en el país. Todo este aumento al tiempo que sube el agua, la luz, el gas, la gasolina y el diesel.

En la medida que el empleo no se recupera con fuerza, que aumenta el subempleo y el costo de la vida se eleva, se estima que el número de hogares en "situación de pobreza"

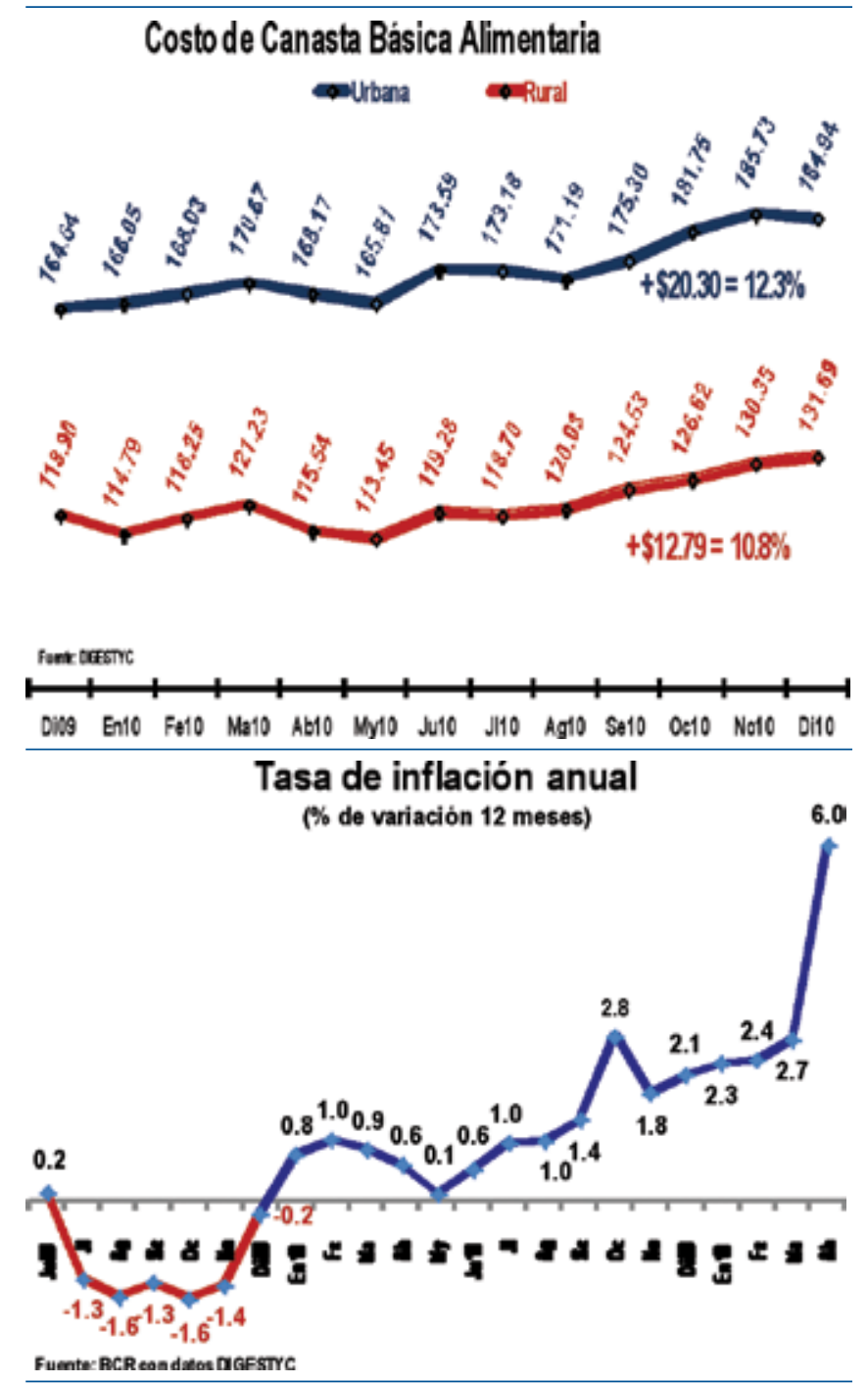

Hogares en situación de pobreza

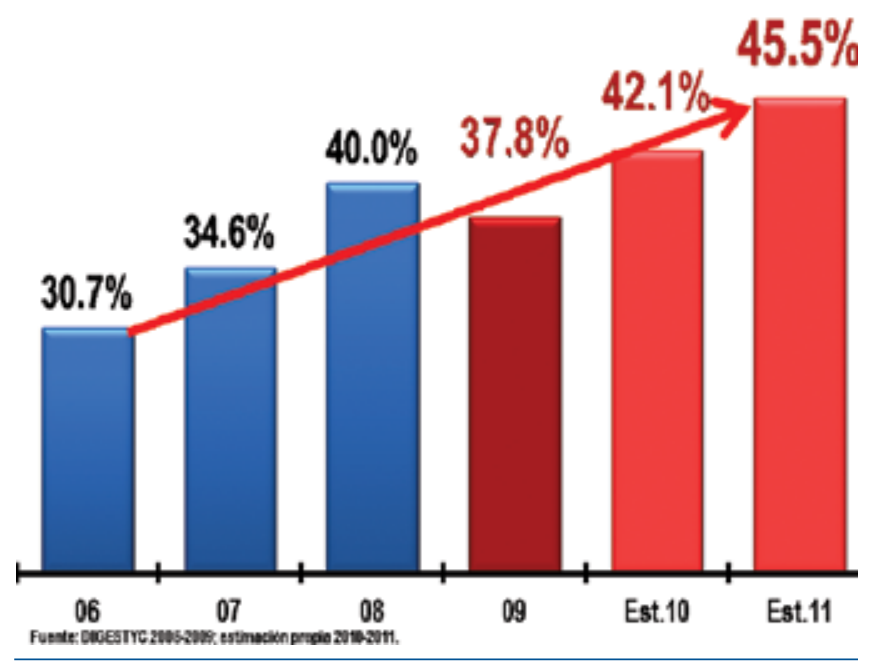


aumenta 7.7 puntos porcentuales en los dos últimos años, esto es, más del $45 \%$ de los hogares estarían en situación de pobreza en 2011. De este modo, estarán viviendo en situación de pobreza unos 700 mil hogares en 2011, que representan 171 mil hogares más que han caído en pobreza relativos a los que estaban en situación precaria en 2006. Esto significa que el país habría retrocedido 14 años, cayendo en una situación sólo comparable con 1997, cuando el 48\% de hogares estaba situación de pobreza.

Mayor inversión: la apuesta estratégica del Gobierno

La estrategia macroeconómica central del gobierno del FMLN para lograr un mayor crecimiento económico se fincó en aumentar la inversión pública para compensar la alicaída inversión privada nacional y mantener o incrementar la inversión privada extranjera directa (IPED). El resultado de dos años de gestión ha sido pobre. Claramente la inversión privada sigue aletargada, la inversión pública es deficiente y la IPED deja de venir porque el país ha dejado de ser atractivo.

En efecto, la "formación bruta de capital fijo", traducido en forma coloquial como "inversión", en el país decrece. Esto es preocupante porque además de ser un indicador general del grado de confianza de los empresarios también expresa el dinamismo futuro que puede adquirir la economía, esto es, su potencial de crecimiento. Aquí entra en juego la percepción empresarial, donde si está sumida en incertidumbre o expectativas de recesión económica, la inversión tiende a bajar; contrariamente y cuando hay confianza tiende a subir.

La realidad de El Salvador muestra que la inversión "privada" cayó de \$1.510 millones en términos reales (descontada la inflación) en 2008, cuando se inicia la recesión, a \$1.212 millones (19,7\% menos) y se recuperó levemente a $\$ 1.243$ millones (\$31 millones o 2,6\%) en 2010. Esta recuperación timorata revela que la inversión privada del último año es aún $17.8 \%$ menor a la de 2008.

Al evaluar la ejecución de inversión "pública", se observa que la estrategia del Gobierno para dinamizar la economía transformándose en un fuerte inversor no fue posible: fracasó. Ella cayó de \$222 millones en 2008 a \$187 millones en 2009 (-15,8\%), algo lógico ente la recesión económica y comprensible por el cambio de Gobierno. Sin embargo, la caída de la inversión privada continúa y se sitúa en \$178 millones $(-4,9 \%)$ en 2010 , revelando un descalabro en la ejecución de inversión pública.

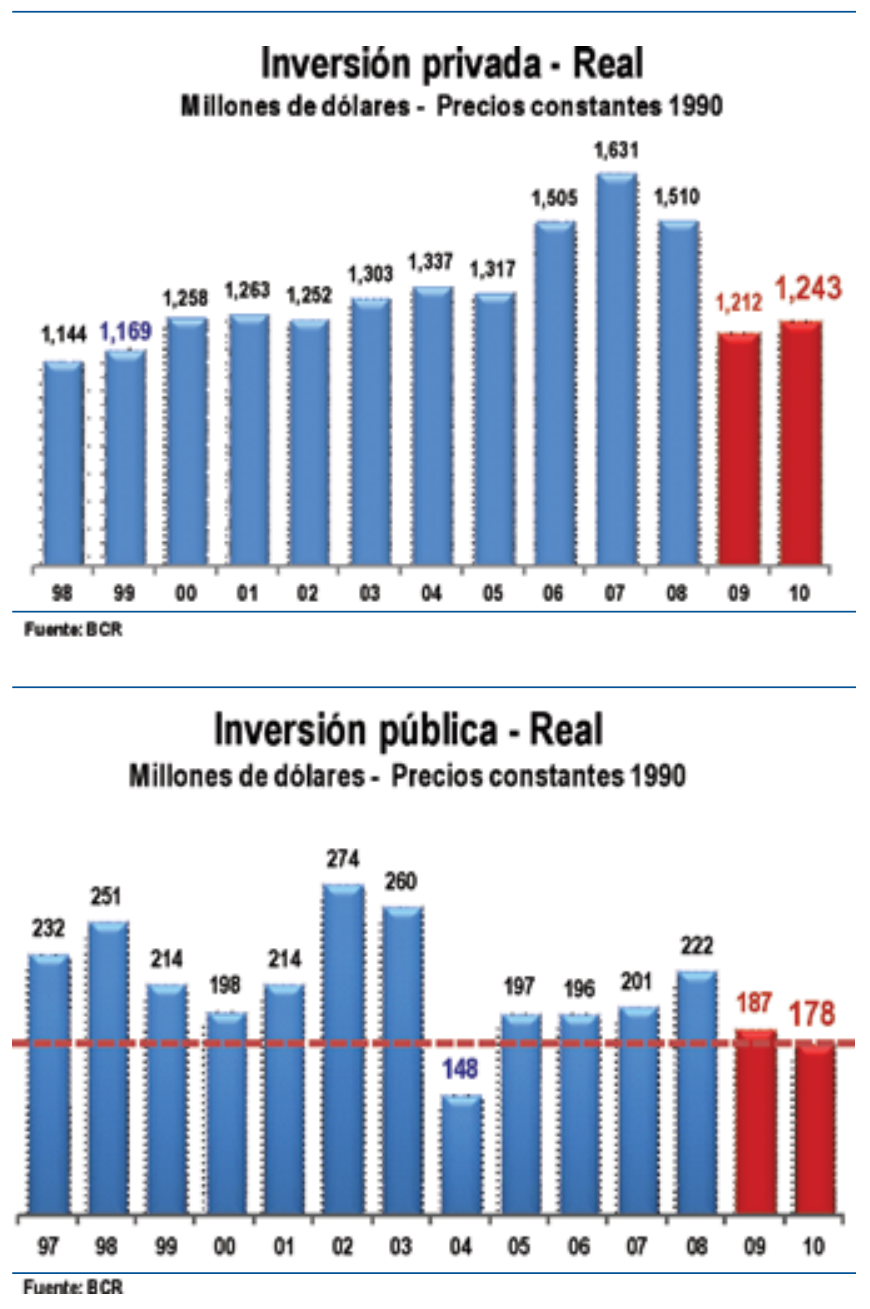


En términos nominales (precios actuales), se tiene que de \$846 millones programados de inversión en 2010 -con recursos disponibles - el Gobierno dejó de invertir \$309 millones, según informe de la Unidad de Análisis y Seguimiento del Presupuesto (Asamblea Legislativa), por su poca "capacidad estratégica de ejecución", por lo que recomendó al Gobierno "revisar los procesos y la capacidad técnica de los ejecutores". El presidente Funes también entró en las explicaciones, pero dejó en el tintero las deficiencias que se tienen por la reducida "capacidad técnica de los ejecutores", resultante del despido o cambio de trabajadores públicos con años de experiencia por razones políticas. Este es un lamentable resultado, porque si no se tiene claro lo que se está licitando, no se puede explicar con precisión lo que se necesita y los requerimientos técnicos, se termina declarando desiertas las licitaciones, haciendo engorrosos los procesos o se tomará más tiempo del necesario. Esto es lo que ocurre ahora.

Es adecuado decir que hay "una falla estructural", donde la Lacap ha sido factor central. Pero es inapropiado señalar que "no es un problema de este Gobierno; gobiernos anteriores también han tenido una baja ejecución presupuestaria". Pero esta explicación deja al desnudo al
Presidente cuando señala: “Desde que asumí el Gobierno dije que necesitábamos hacer una reforma administrativa de fondo, que permitiera contar con un gobierno más eficaz y más eficiente". Increíblemente han pasado dos años y recién busca corregir lo que sabía desde el primer día de gestión, teniendo el caudal político necesario para hacer la reforma necesaria. ${ }^{1}$

El tercer objetivo era mantener el flujo de IPED, pero también se convirtió en un fracaso. El Salvador era un país atractivo, con grado de inversión, avanzando en competitividad y desarrollo humano e incluso logró ubicarse entre los diez países económicamente más libres del mundo. Todo esto se perdió y la confianza de invertir en El Salvador se esfumó. Los datos del reciente informe de la Cepal son demoledores. La IPED cayó de \$1.508 millones que ingresaron en 2007, antes de la recesión, a \$784 millones —inicio de recesiónen 2008 , a $\$ 431$ millones en 2009 , y luego se hunde hasta $\$ 89$ millones en 2010 -menos $79,5 \%$ - Esto se debe fundamentalmente a la incertidumbre que genera el Gobierno así como la falta de un plan para atraer la inversión extranjera, con apuestas específicas, como se ha visto recientemente en Honduras y en Guatemala.

\section{Inversión Extranjera Directa}

Ingresos acumulados - millones de US\$

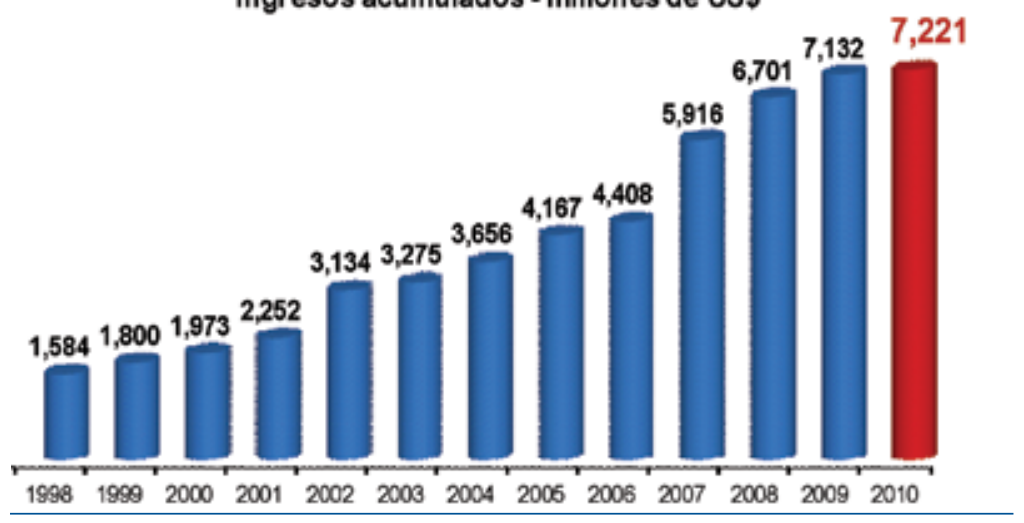

Fuente BCR.

1 La reciente reforma es parcial y está fundamentalmente dirigida a las necesidades de compras del sector salud, pero la reforma mayor aún está pendiente. 
Si se compara esta IPED en El Salvador con la que recibió el resto del Istmo se ve claramente que somos los últimos. En 2010, la IPED que llegó a Panamá fue de \$2.363 millones (un aumento de $+33 \%$ ); Costa Rica $\$ 1.412$ millones $(+7 \%)$; Honduras $\$ 798$ millones (+52\%); Guatemala $\$ 678$ millones (+18\%); y Nicaragua $\$ 508$ millones (+17\%). Al ver el volumen de IPED captadas por Honduras -saliendo de una profunda crisis política-y de Nicaragua -la economía más pequeña de Centroamérica y con gobierno de "izquierda"- ¿quién puede tener la responsabilidad del descalabro en la inversión en El Salvador después de sólo dos años de gobierno del FMLN? Claramente, no es por razones ideológicas que la Iped dejó de venir a El Salvador.

\section{Aumenta deuda con baja inversión pública}

Al actual Gobierno se le ha aprobado la mayor cantidad de recursos provenientes de créditos en la historia de El Salvador, para reactivar la economía y apoyar diferentes programas sociales. Lo aprobado entre mayo 2009-2011 alcanza a \$4.374.2 millones (Cuadro 2). Además, el Gobierno está negociando otros $\$ 835$ millones, que de aprobarse llegarían a un total de $\$ 5.209 .2$ millones, que representan unos 25 puntos del PIB.

Sin embargo, de este monto aprobado hay que descontar los préstamos reprogramados en 2009 (\$383.0 millones), y los que corresponden a otros compromisos, por un total de $\$ 510.5$ millones. Entonces, lo aprobado y disponible para el Gobierno suma $\$ 3.4080 .7$ millones (más de 16 puntos del PIB) y que, de aprobarse los $\$ 835$ millones en negociación, el total disponible se elevaría a \$4.315.7 millones, equivalentes a unos 20 puntos del PIB, lo que lo lleva camino a ser el gobierno que más se ha endeudado en la historia de El Salvador.
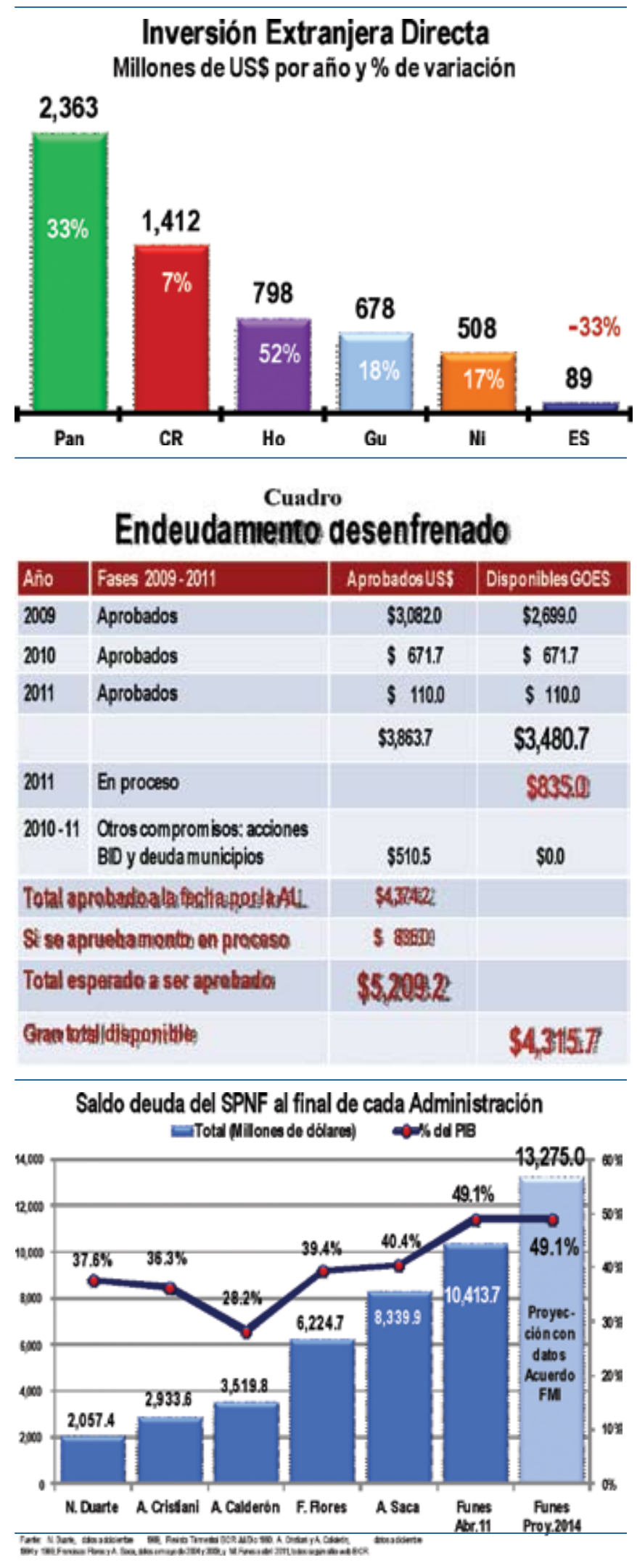
Por su parte, la deuda pública total ya llegó a \$10.413.7 millones a abril de 2011, lo que muestra que el Gobierno del FMLN ha endeudado al país en \$2.074 millones en 23 meses de gestión, sólo \$41.4 millones menos que el endeudamiento total del quinquenio de la admininstración del presidente Antonio Saca. La deuda crece $\$ 3.4$ millones diarios.

A este ritmo de endeudamiento, lo más probable es que al cierre de los dos años ya haya superado el endeudamiento de los cinco años del gobierno anterior y que alrededor de septiembre ya haya sobrepasado al gobierno de Francisco Flores, que debió afrontar la reconstrucción del país por los dos terremotos de 2001.

Sin embargo, este gobierno muestra una ejecución mediocre de la inversión pública (algo más de 60\%), cuando en los últimos dos años del gobierno anterior ya se había logrado ejecutar sobre $70 \%$. Entonces, la pregunta obvia es que si la deuda crece tan fuertemente y la inversión es mucho menor a lo presupuestado ¿qué ha pasado, a dónde han ido a parar estos recursos? La respuesta apunta a que una parte significativa del endeudamiento se ha utilizado para pagar "gasto corriente". Recuerdo una entrevista en Canal 21 al candidato Mauricio Funes, que condenaba el endeudamiento para financiar "gasto corriente", aseverando que el "FMLN nunca" apoyaría préstamos para este tipo de gasto. ¡Cómo cambia la vida! De lo que ayer se condenaba, ahora se abusa sin medida.

Preocupa que el endeudamiento se aproxima con celeridad a niveles de insostenibilidad fiscal, ante una reisgosa irresponsabilidad fiscal. Si la inversión no se recupera y no logra crecer la economía con fuerza - por ahora muy lejos de eso-, y si no se crean más empleos y aumenta el consumo, difícilmente subirá la recaudación tributaria, y El Salvador seguirá el camino de muy alto riesgo como país.

\section{Endeudamiento SPNF en cada gestión \\ (Millones de dólares)}

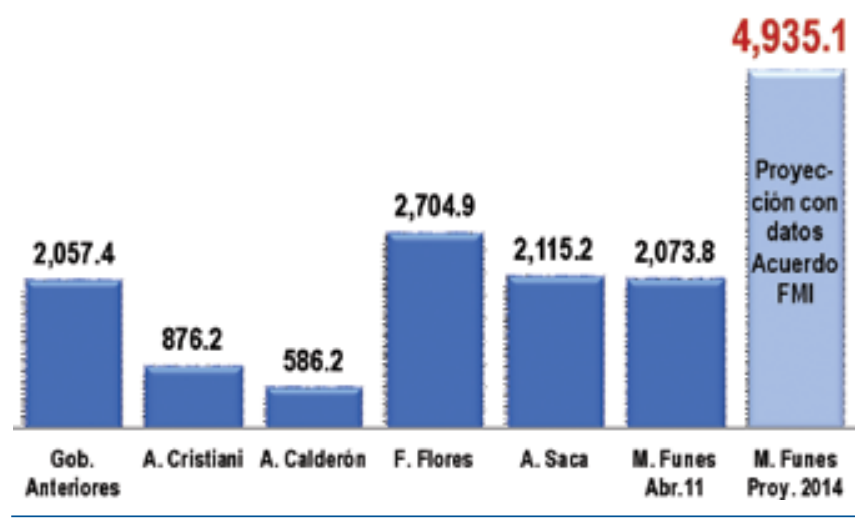

Sector externo con fuerte recuperación hala la economía

Los resultados más positivos provienen del sector externo con una recuperación de las exportaciones, que crecieron 16,4\% en 2010 y una más lenta pero importante alza de $2,4 \%$ de las remesas familiares. Sin embargo, los buenos resultados en estos dos componentes del sector externo se vieron disminuidos por el leve crecimiento de la inversión privada extranjera directa, que sólo sumó $\$ 89.0$ millones en 2010.

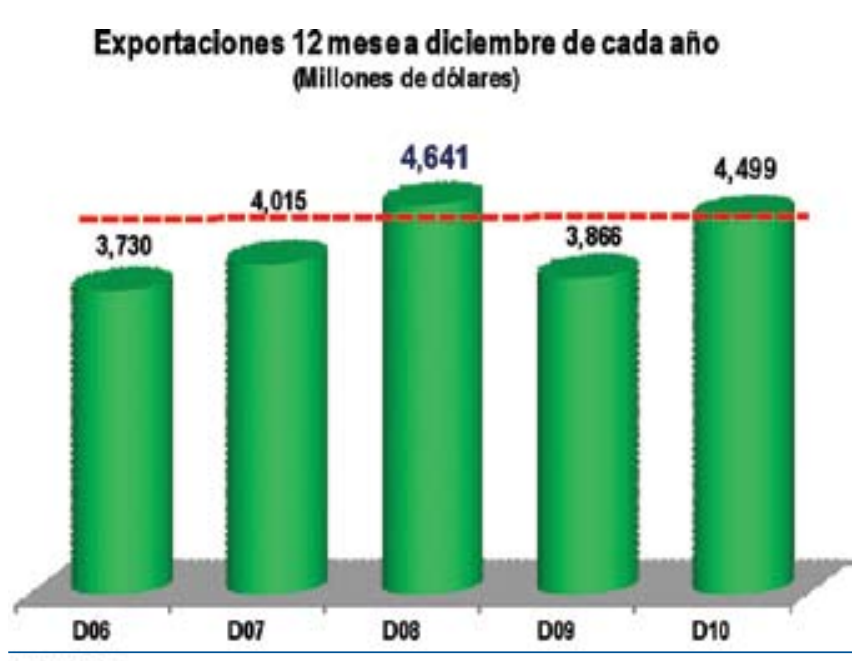


Las exportaciones salvadoreñas alcanzaron $\$ 4.499$ millones en 2010 , con un alza de $16.4 \%$ respecto a 2009 , cuando ellas se contrajeron $-16,7 \%$. Si bien estos resultados son alentadores, se tiene que lo exportado el último año es aún $-3,1 \%$ menos que lo realizado en 2008 .

Por su parte, las importaciones totalizaron $\$ 8.498 .2$ millones en 2010, que representan un aumento de $16,0 \%$ respecto 2009, en gran parte explicado por el aumento de la factura petrolera y de las importaciones de maquila, asociada por un repunte de la actividad económica en los Estados Unidos de América.

Remesas familiares con leve aumento

Las remesas recibidas alcanzaron un total de $\$ 3.481 .3$ millones en los 12 meses a abril de 2011, lo que refleja un aumento de 2,4\% respecto al mismo período de 2009 , cuando cayó $5,9 \%$ después de la baja de $4,0 \%$ e 2008. Este resultado es, principalmente, reflejo de una disminución importante del desempleo hispano en EEUU.

El monto de remesas recibidas en los 12 meses a abril de 2011 — salvo en 2010-sólo supera los ingresos captados en 2006. De este modo, las familias salvadoreñas recibieron \$282.7 millones menos en los 12 meses a abril de 2011 relativos al récord de $\$ 3.764$ millones en 2008 , lo que afecta adversamente su capacidad adquisitiva.

Crédito al sector privado deprimido y dinero se contrae

El crédito neto de bancos y financieras al sector privado (empresas y particulares), después de dos años de contracción se estanca en abril de 2011, al ubicarse en
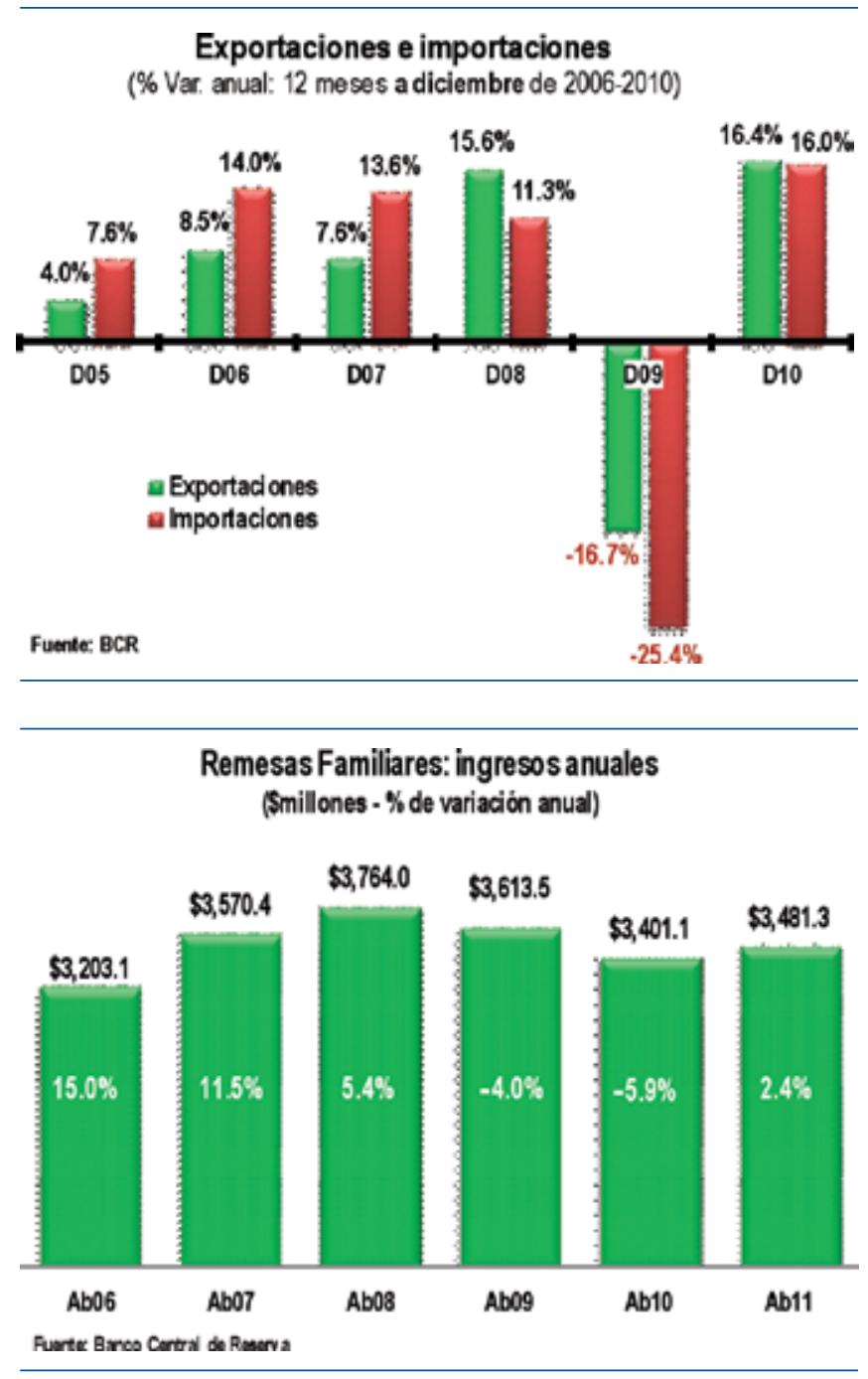

\section{Crédito al sector privado a abril de cada año Saldo - Millones de \$}

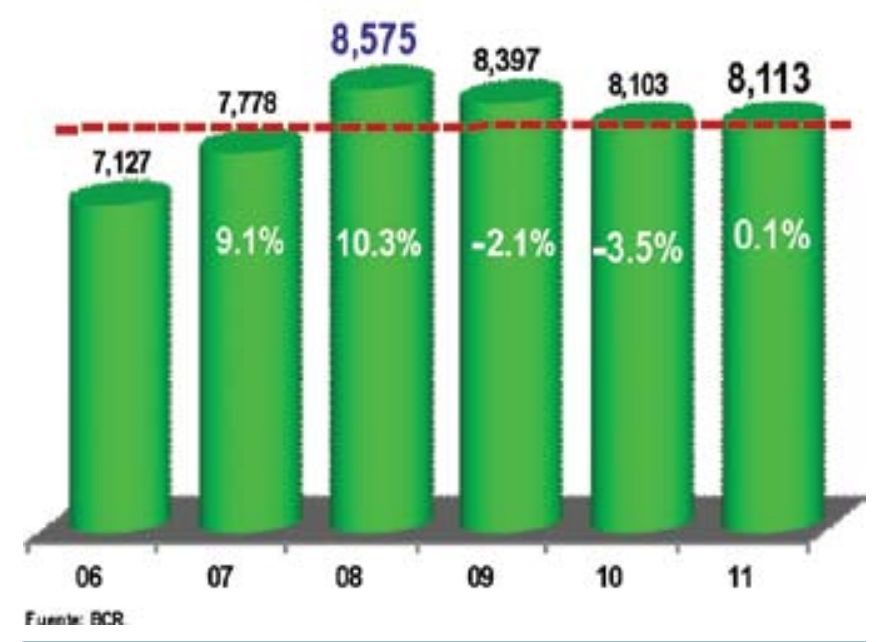


$\$ 8.113$ millones comparado con $\$ 8.103$ millones a ese mismo mes de 2010, lo cual representa un magro aumento $0.1 \%$, después de las caídas de $-2,1 \%$ en 2009 y $-3,5$ en 2010 , lo cual contrasta claramente con los fuertes aumentos del crédito a abril de 2007 y 2008.

La marcada reducción del crédito a empresas y particulares entre abril de 2008 y de 2011 ( $\$ 462$ millones menos, que equivalen a alrededor de 2,2\% del PIB) está asociada principalmente con una menor demanda y la falta de confianza que prevalece en el sector privado por una combinación de mayor tasa de desempleo y por la incertidumbre que causan los altos índices de delincuencia, crecientes extorsiones y secuestros.

Los depósitos (i.e., en cuenta corriente, de ahorro y a plazo) y títulos del sector privado, que constituyen la principal fuente de financiamiento del crédito para las instituciones financieras, cayeron por primera vez a abril de 2011 desde antes de la recesión económica, contradiciendo que se hubiera "salido de ella" en 2010 como lo asevera el BCR. De $\$ 9.435 .3$ millones en depósitos y títulos valores a abril de 2010 se redujo a $\$ 9.274 .6$ millones a este mismo mes de 2011 , reducción equivalente a $-1,7 \%$ anual, preocupante variación considerando que en los dos años anteriores hubo una desaceleración, pero se mantuvo un aumento de 1,3\% en 2009 y 1,3\% en 2010. Esto debería ser de profunda

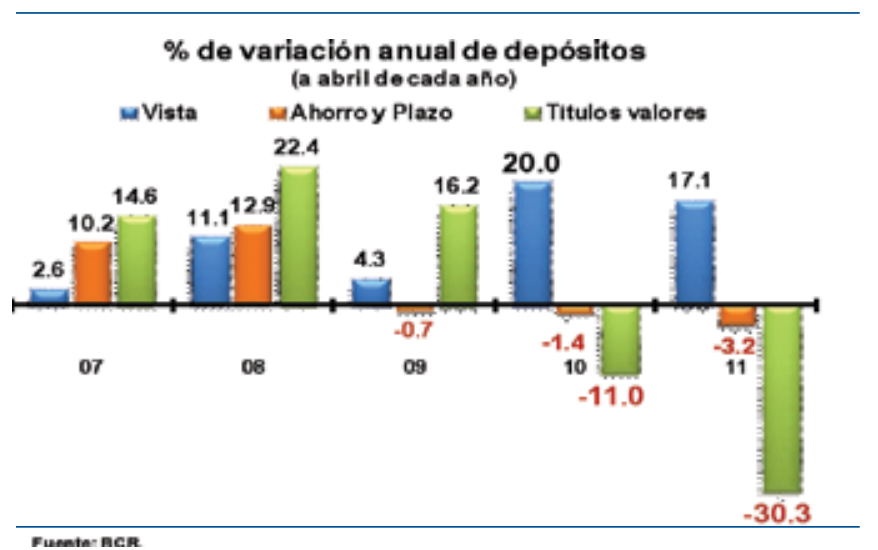

Entorno ISSN: 2218-3345

\section{Sector privado: depósitos y títulos valores} En millones de dólares a noviembre de cada año

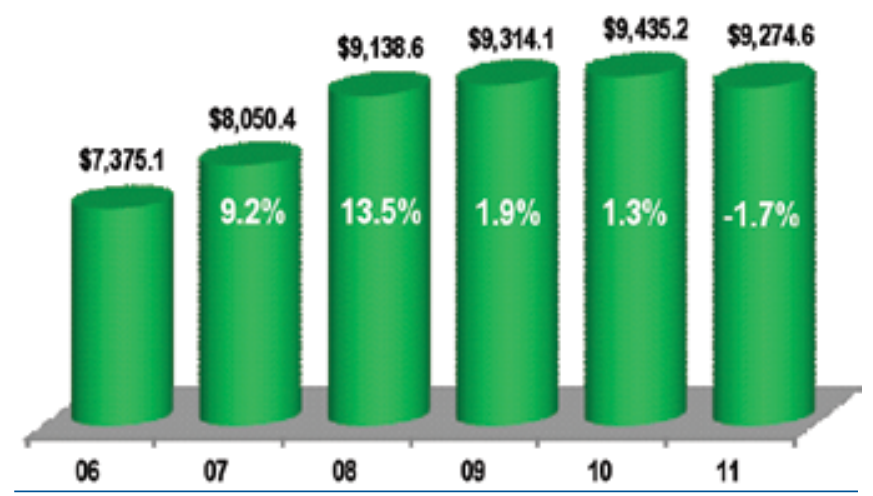

Fuente: BCR

preocupación para la autoridad monetaria por la señal que envía y lo que puede significar en términos de presión al alza en la tasa de interés.

Mayor preocupación debe producir que esta variación anual se dé en el marco de una tendencia de contracción de los depósitos de ahorro, por tercer año consecutivo y un desplome de los títulos valores, que son un indicador general de confianza financiera y mayor certidumbre para los bancos. Ante una preferencia del público hacia los depósitos a la vista en vez de depósitos a plazo y títulos valores, se produjo un cambio en la estructura de los depósitos, donde los primeros aumentaron su participación de $17,5 \%$ a febrero de 2009 a 25,3\% a en igual mes de 2011, lo que significa que las instituciones financieras están entrando en mayor riesgo al conceder créditos a largo plazo con recursos que no son ni siquiera de corto plazo, sino que a la vista.

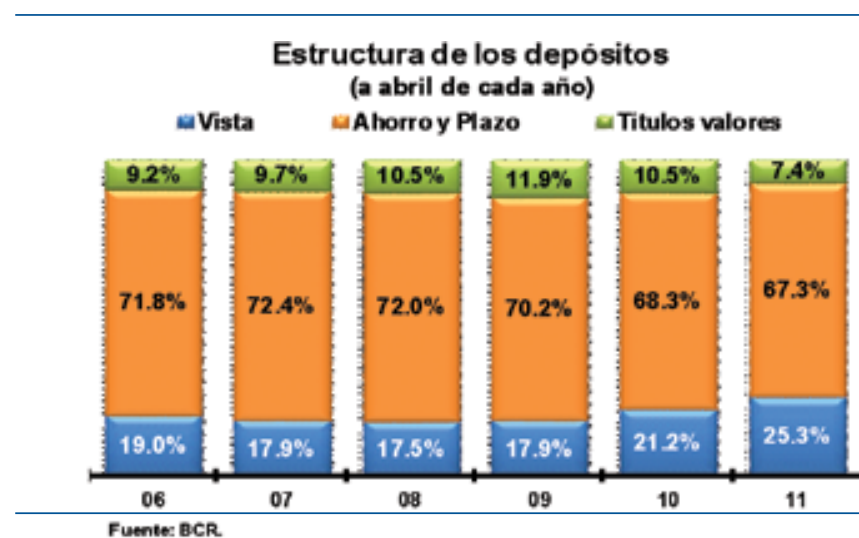


Dos años de Gobierno del FMLN: incertidumbre, poco avance y mala calificación de la gente

A dos años de Gobierno las más importantes promesas han quedad sin cumplir y como recuerdo para la historia de El Salvador, otras aún no se inician, algunas están en vías de cumplimiento y muy pocas están cumplidas. La delin-cuencia va en aumento, lo que siembra la angustia en muchas familias; la inversión no se da en los montos necesarios para que la economía crezca, por lo que no se logra reducir con fuerza el desempleo y el sub empleo. A esto se agrega que el costo de la vida aumenta, por lo que muchas familias están cayendo en situación de pobreza. Todo agravado por una situación financiera del Gobierno que va camino a una crisis fiscal que nace de un endeudamiento exorbitante por un gasto que no se puede poner en cintura e ingresos que no aumentan porque la economía sigue estancada. Esto crea incertidumbre, lo que frena el crecimiento económico, empujando al país a un círculo vicioso que lo tiene estancado.

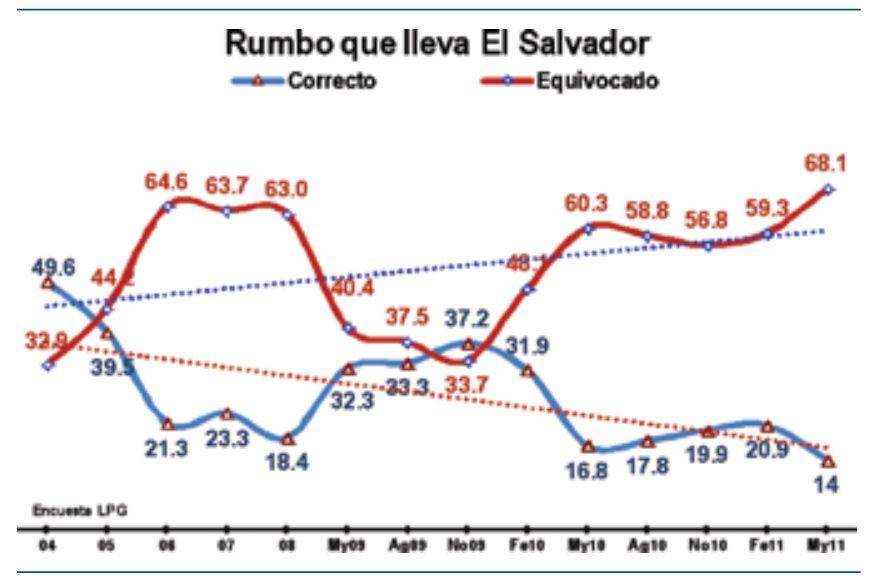

Presidente está resolviendo los problemas económicos

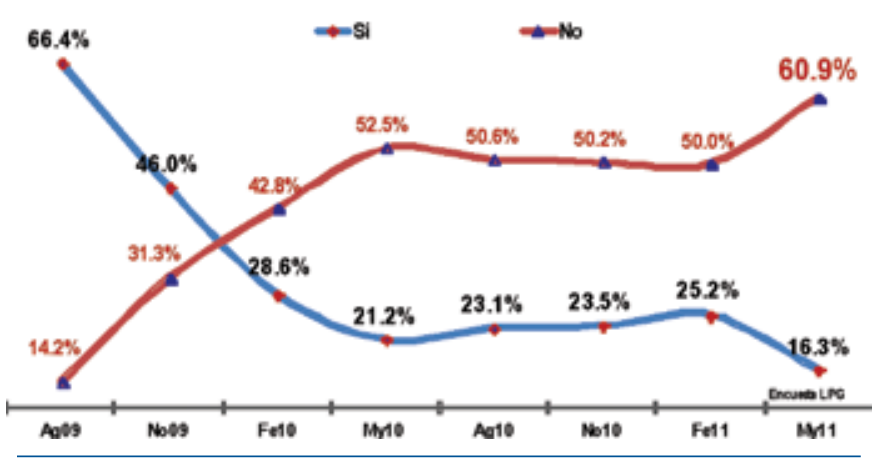

Pasado dos años de Gobierno del FMLN la opinión pública le ha dado, en general, las peores evaluaciones, que en casos son las más malas desde 2004. Las encuestas de LPG-Datos y la de Mitofsky, muestran un gran paralelo sobre la clara insatisfacción que tiene la gente sobre la situación general y sobre el rumbo equivocado que lleva el país. Las calificaciones muestran un marcado deterioro en todas áreas de gestión, donde tienen buena nota salud y educación, aunque deteriorándose en las encuestas a mayo de 2011. Los cuadros hablan por sí solos.

El Gobierno tiene una tarea formidable para recuperar su imagen, la que no se logra con avisos comerciales, sino que generando resultados, cumpliendo promesas, escuchando a la gente y alejándose de la confrontación. Sin dudas llegó el momento actuar con sensatez, de reflexionar y corregir.

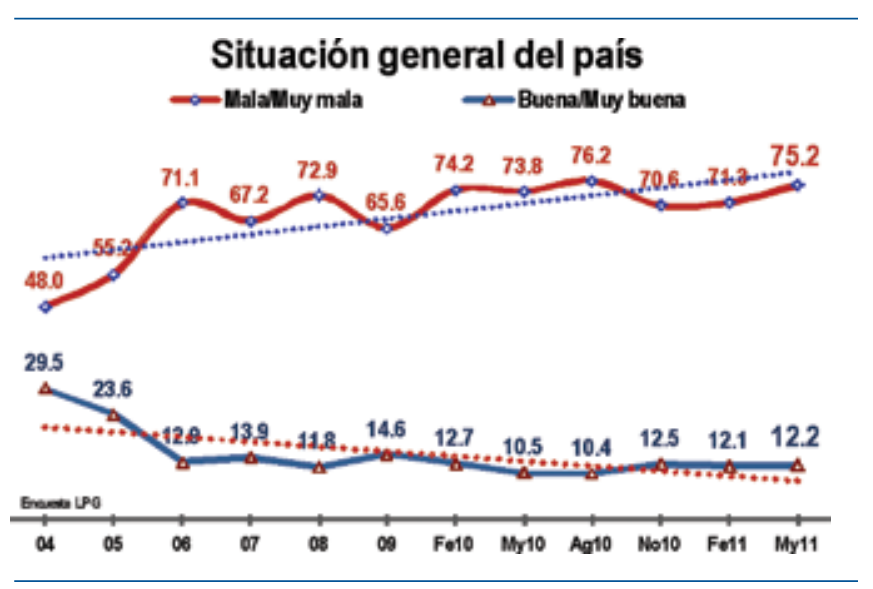

Situación económica respecto a un año

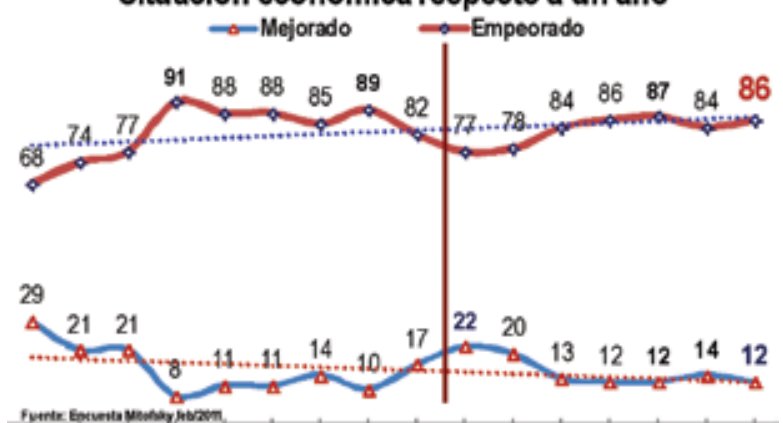

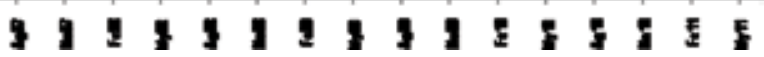



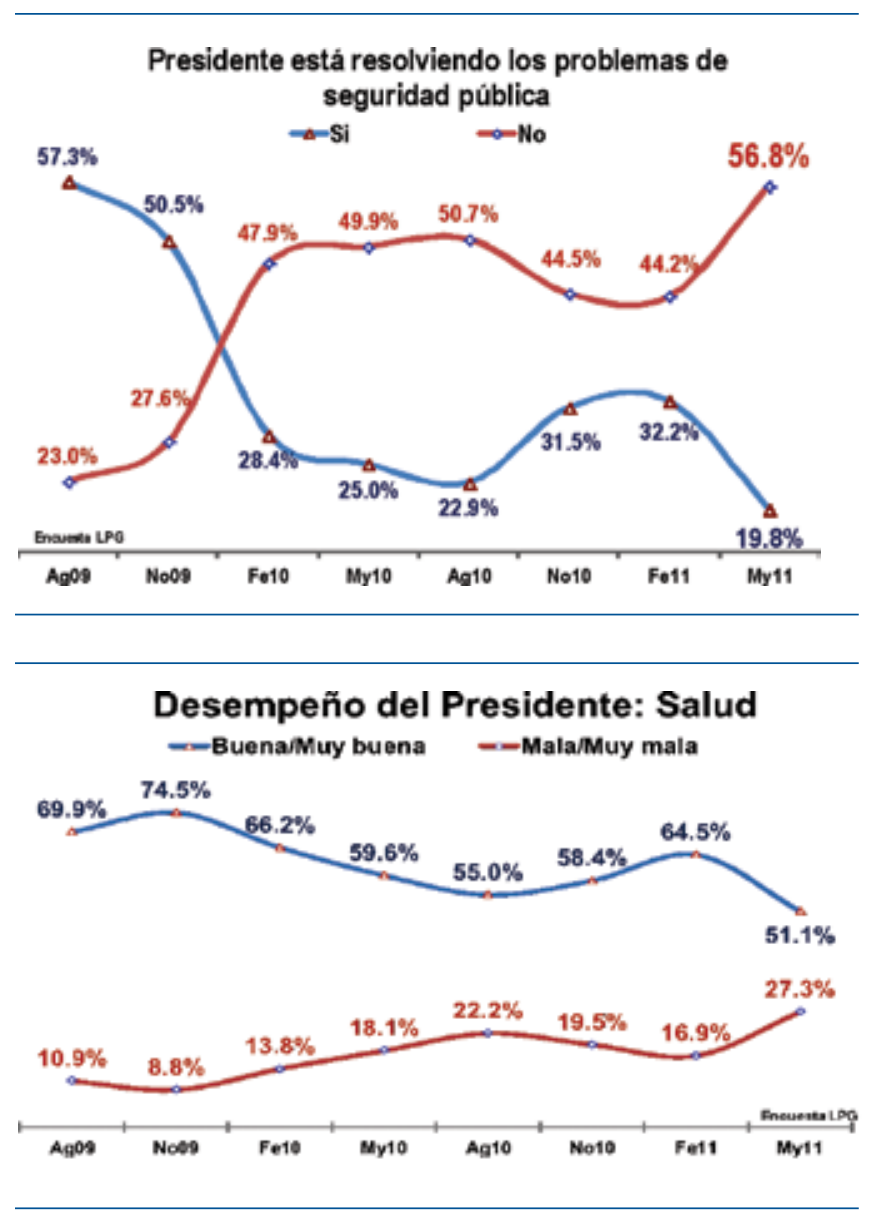
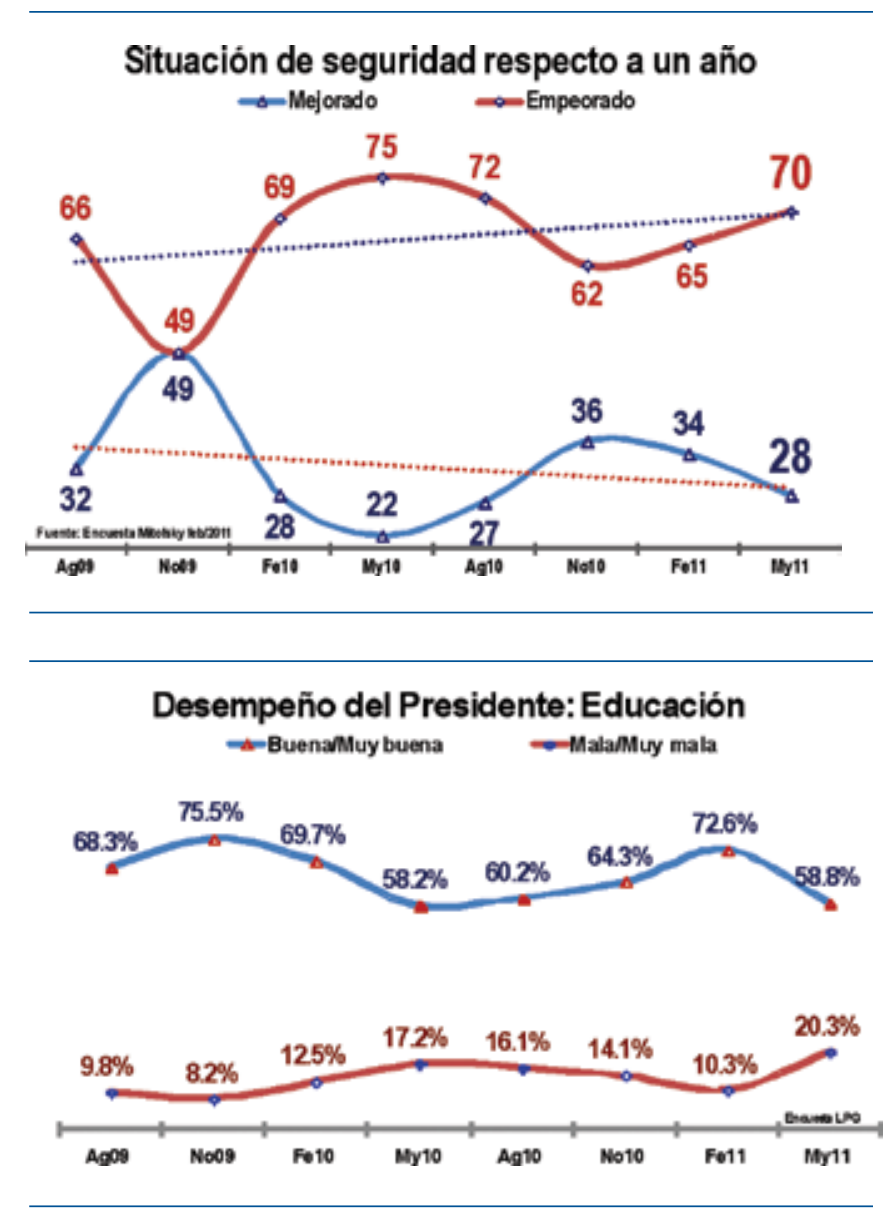